\title{
Signa $^{\mathrm{TM}}$ - Towards Electronic Document Cross- Border Interoperability
}

\author{
Jeremy Besson ${ }^{1}$, Adomas Birstunas ${ }^{2}$, \\ Antanas Mitasiunas ${ }^{3}$, Arunas Stockus ${ }^{4}$, \\ 1,2,3,4 Vilnius University, MitSoft Ltd, Lithuania
}

\begin{abstract}
Transfer of information-based services to an electronic environment is the accomplished fact. Some of such services lead to creation of electronic documents that are signed by qualified e-signature and have legal value equal to handsigned documents. In fact, the documents are created not for private use but for an exchange with the others. The main challenge of the electronic document usage is their interoperability. An electronic document is a dual technical and legal artefact that depends on a national legislation system and "lives" within a national platform of electronic documents. Therefore, an electronic document is not a subject of technical standardization only. The paper introduces a new concept for an electronic document cross-border interoperability solution based on creation of original copies for each national electronic document platform of the document signatories.
\end{abstract}

Keywords - Electronic documents, interoperability problem, qualified e-signature.

\section{INTRODUCTION}

Today even most advanced institutions propose such a document processing procedure: to download document templates, fill templates, print, sign, stamp, scan, send scanned files and send original paper documents by ordinary post. This procedure means that legal power of the documents is still important. As scanned copies lack legal power, legal certainty requires presence of original documents.

This procedure also means that typing machines are not used any more. Nowadays content of a document is created using IT in an electronic environment. However, in order to empower a document it is transferred to a paper environment by printing to enable its signing by a handwritten signature. Again nowadays for efficiency reasons everybody tends to avoid working with paper documents. This is why original paper documents are transferred back to an electronic environment by creation of scanned copies frequently of poor quality and with limited processing possibilities.

Such a procedure is presented even as an innovation that allows saving time and money if original documents are not needed for decision making and if to compare with processing of paper documents.

However, detailed calculation shows that in the case of country with population of 3 million, like Lithuania, the document scanning labor costs only exceed $10 \mathrm{M} €$ per year. In the European Union, such a procedure costs a few billion yearly. But the scanned paper copies are not enough. Some eservices, such as e-Government, e-business, e-commerce and others, are impossible without official electronic documents having legal value equal to hand written documents [1].

Comprehensive comparison of processing costs of invoices in paper media and electronic media was made by B. Koch [2]. It was found that the cost saving for issuance of one electronic invoice instead of paper one was $6.40 €$. The cost saving per invoice for recipient is even bigger and it is equal to $10.90 €$.

Apart from obvious benefits of electronic documents, like cuts in many ways of paper expenses and growth of productivity, another major characteristic of the electronic document management is the return-on-investment (ROI): average 3-year ROI is exceeding $300 \%$ [3]. Thus, it is completely clear that electronic documents everywhere will replace conventional documents.

Therefore, there are no other reasons to use electronic documents as costs and time saving. Scanned copy-based intermediate solutions still exist only for one reason - to lower innovation threshold. In fact, the procedure mentioned above document content transfer from electronic media to paper media to ensure legal power and then to transfer from paper document to its electronic copy for processing can be treated even as anti-innovation.

The true innovation is that the second and third steps of this procedure simply are not needed and can be skipped by creation of electronic document signed by a qualified electronic signature having the same legal power as handsigned signature directly in the first step.

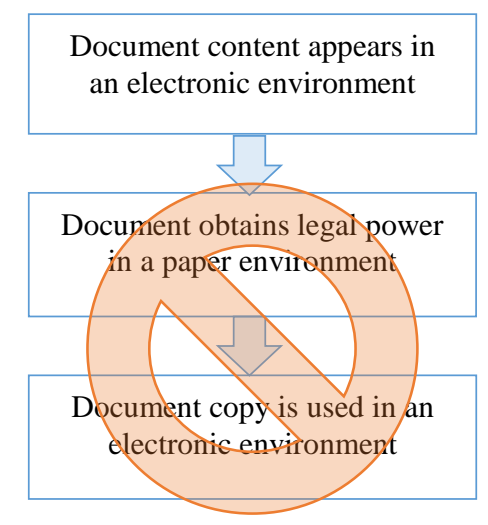

Fig. 1. Comparison of two ways of document processing.

\section{INTEROPERABILITY PROBLEM}

Article [8] on electronic procedures of the Service Directive [4] had to be fully implemented by the EU Member States by 
the end of 2009. However, the cross-border electronic document exchange among the Member States is still challenging. Although targeting of large-scale projects [5], [6] has been conducted or is in progress, the question of crossborder electronic document exchange is still open. At the moment, most of the EU Member States are still in the process of defining a clear strategy of the official electronic documents and their usage in daily communication between businesses, citizens and public sector.

Despite obvious benefits of electronic documents and serious efforts taken to facilitate usage of electronic documents, their usage is still quite limited. Why?

Essentially a document is the message for others. The documents are created not for private use but for exchange with the others. An essential feature of a document is its interoperability. If a document does not possess interoperability feature it cannot play the role of a document such a document cannot be used. Therefore, the main challenge of using electronic documents is their interoperability.

The study on electronic documents and electronic delivery for the purpose of the implementation of the Services Directive, focusing specifically on the availability, use and delivery of electronic documents [7] shows that achievements of Member States are quite different.

Interoperability related issues have several aspects. Understanding of electronic document interoperability depends on understanding of electronic document itself.

\section{A. Concept of Electronic Documents}

First of all, an electronic document is a document that is implemented in electronic media. Media is not a part of document concept. Paper media or electronic media are alternatives for document implementation.

Concept of the electronic document should be adequate to the real document. A real document is a very complex entity. The document provides some content that may consist of the texts, spreadsheets, tables, calculations, drawings, pictures etc. provided as a main document, appendices or attached independent earlier created documents. In turn, the appendices may possess their own appendices and so on. Attached documents may also possess other attached documents and so on. The documents having legal power in an open environment must be signed by one or more signatures. A signature expresses the conscious and voluntary will of the signatory to approve the content signed. Official documents achieve legal value only after signed documents are registered, i.e., included into account by public sector institution, and possess the required metadata attributes, for instance, document registration number and date. In general, a document consists of three parts: content, signatures and metadata.

Therefore, an adequate electronic document in an open environment having legal power equal to hand-signed document should be a very complex entity, too. It must also consist of content, signatures and metadata. However, usually these three areas are addressed by three different fields of interests - document processors, electronic signatures initiatives and record management systems that are standardized separately, i.e., file formats, electronic signatures formats and metadata are standardized separately, but the signed electronic document format as a combination of all three parts is not standardized. An electronic document, being adequate to a document, has a complex life cycle starting from document creation, including sophisticated document creation procedure, usage, storage, until destruction if a document has a limited life cycle. Long-term retention of electronically signed documents brings certain problems [8]. An electronic document is not some instantaneous snapshot as it is sometimes represented.

\section{B. Open Systems vs Closed Systems}

The state of the art in the interoperability solutions of electronic documents can essentially be characterized as closed system solutions, i.e., interoperability or accessibility of electronic documents is ensured within a closed system. Expanding of interoperability limits can be reached by expansion or integration of closed systems.

Functioning of closed system is based on prior agreements of closed system participants. Such agreements legitimize rules of electronic document processing within closed systems. Eligibility of such internal rules is foreseen by legal acts.

The closed systems appear as a result of an easier solution that can be implemented locally by a closed community. Closed system solution is always a temporary solution because closed system participants' needs are never limited locally only. Therefore, a closed system solution should be treated as a partial solution.

\section{Standard-Based vs Product-Based Interoperability}

The electronic document interoperability feature influences even an understanding of an electronic document as such. The interoperability is ensured if an electronic document is created and accepted using the same document processor. This circumstance is considered a reason to accept a document processor format as an electronic document format. In fact, the equating of an electronic document and a format of a document processor is one of the main obstacles for electronic document evolution and interoperability problem solution. By definition, an electronic document is not a format of some word processor. It is important to emphasize that an electronic document definition is primary and the software for electronic document processing is secondary. Electronic document interoperability within a closed system is based on a software solution.

It is possible to state that a currently dominating trend in electronic document interoperability solution is software product based interoperability. The whole evolution of interoperability related solutions indicates that the product based interoperability is temporary dependent on a product life cycle. Such evolution ends by acceptance of a standard based interoperability approach.

The roadmap to the solution of electronic document interoperability problem goes through the standardization of electronic document attributes. 


\section{Electronic Signature vs Electronic Document}

The main standardizations efforts in the EU are still targeted to electronic signature formats. Decision 2011/130/EU [9] obliges the Member States to be able to technically process most common formats of advanced e-signatures XAdES [10], CAdES [11], and PAdES [12]. But the true artifact of interoperability is an electronic document. The obligation to process electronic documents signed by electronic signatures of common formats predefines the formats of electronic documents too, like PDF [13], [14] or XML, or an electronic document embedded into an electronic signature.

The standardization of electronic document attributes does not mean that interoperability issues of electronic documents can be substituted by interoperability of separate attributes of electronic documents. Standardization of electronic document attributes facilitates the recognition and verification of electronic document defined by a specification of electronic documents.

\section{E. National Platform of Electronic Documents}

An electronic document is dual legal and technical artefact that depends on a national legislation system and "lives" within a national platform of electronic documents. The definition of an electronic document is a sovereign right of each country. Therefore, an electronic document as such is not a subject of technical standardization only. The attributes of electronic documents can be standardized.

At the same extent, as the existence of various national legislation systems is natural and it does not require any justification, the existence of various national platforms of electronic documents is natural, too.

Namely, an attitude to a national platform of electronic documents is the differentiating point to the understanding of electronic document interoperability problem, i.e., if to ignore the existence of different national platforms of electronic documents, then new formats of electronic documents can be introduced easily without support of such format functioning by a platform. Understanding of the role of national platform of electronic documents is closely related to the understanding of an electronic document as such.

In reality, there are two essentially different understandings of electronic document. The first is mentioned in the section "Concept of Electronic Documents", i.e., a document is invariant to its media. The special legislation for electronic documents is not needed and even it is not feasible. The analysis performed shows that in the case of the UK legislation in 40 thousand instances the media is mentioned [15]. All these instances are related to a quite small number of document attributes. It is sufficient for each such attribute to establish equivalency conditions for corresponding attribute in electronic media.

According to the second attitude, the essential part of the document is its media, i.e., electronic media is specific and, therefore, electronic documents possess features different from those of paper documents. Usual approach is that electronic documents are better or can omit some document attributes only because of electronic media. For instance, not signed electronic document of the state information system is equated to a document having an electronic signature.

In fact, such additional rules are valid in a closed system environment only.

The key challenge for the solution of electronic document interoperability is the existence of different national platforms of electronic documents. Otherwise, such a solution would be trivial. It is sufficient to establish a uniform platform of electronic documents in communicating countries, and the problem of electronic document interoperability disappears.

According to the EU legislation, the requirement for uniformity of national platforms of electronic documents is not also applicable to the scheme of electronic identification of the citizens of the EU Member States.

National platform of electronic documents is an environment, in which a document functions from its creation until destruction, if such a document is not of permanent preservation. Each document belongs to some national legislation system. An electronic document cannot "live" without a national platform of electronic document. An electronic document can be created only for demonstration purposes but not in support of real processes without having a national platform of electronic documents.

\section{STANDARD-BASED INTEROPERABILITY SOLUTIONS}

The classification of interoperability solutions is provided in [16]. According to [16], the interoperability of electronic documents could be achieved by two essentially different ways:

- Integrating the existing electronic document solutions;

- Defining and implementing the new standard electronic document platform.

The integration of existing electronic document solutions depends on the number of different countries of document signatories.

One document exemplar approach can be employed when a document is prepared and signed by one country and delivered to other countries. It assumes that a document is prepared in the national document format of the sender's country using the existing tools for the preparation and signing of electronic documents. In this case, the receivers need the services for such electronic document validation, preview and content extraction.

Separate exemplar approach is proposed for the case when the same document should be signed by the representatives of different countries. In this case, the document exemplars in each country format are prepared and all of them are signed by the representatives of all countries using existing tools of each country.

Other two approaches assume the definition of the new standard electronic document platform consisting of the official document format specification and tools for preparation, signing, preview and verification of such official electronic documents.

Universal electronic document model should be sufficiently powerful to address the needs for complex electronic documents operated by public sector institutions, including 
the whole life cycle documents, i.e., such electronic documents should be completely adequate to official paper documents and could be applied for all cases.

The universal electronic document model is complex but such complexity should be hidden from the users by an electronic documents processing tool. A complex format of electronic document does not necessarily cause the complicated usage of the supporting software.

On the other hand, some partial simpler case can employ a partial document model that is traditionally based on a portable document format (PDF) [13]. PDF based practice belongs to product based interoperability solutions. Definition of PDFbased electronic document specification in terms of electronic document content, signature and metadata instead of tool action terms can transform a PDF based approach to a standard-based interoperability solution.

In general, there are two main trends in the evolution of electronic document formats that can be called ZIP-based and PDF-based electronic documents formats. Universal electronic document model should be sufficiently powerful to address the needs for complex electronic documents operated by public sector institutions, including then whole life cycle of documents. These requirements could be expressed in a quite natural way by the ZIP-based packages.

\section{A. ZIP-Based Document Container}

ZIP-based format is the main trend of evolution of file formats of document processors, such as MS Office and Open Office.

ZIP format is most powerful and flexible to respond to the needs of universal electronic document model. The universal document model should ensure the adequacy of electronic documents to official paper documents and it should possess at least the following properties elaborated:

- Complex document content allowing the primary document content, the appendices with possibly their own appendices, the attached previously created documents having the complex structure too;

- Metadata needed for the document operation during the whole life cycle of document;

- Several signatures, support for parallel signatures and nested signatures. Each signature can sign the whole document or some selected parts of it. Standard signature format, e.g., XAdES, assuring a possibility to preserve the integrity, authenticity, non-repudiation for a long or unlimited time.

Such electronic documents are suitable for all cases, so they inevitably are complex. This approach requires the development of new standard document specification, supporting software and transition to it.

The evolution of such electronic document specification in Lithuania, initially defined based on [17], is influenced by ETSI standardization efforts ASiC [18]. ASIC conformant electronic document specification ADOC-V2.0 is developed and approved by the Chief Archivist of the Republic of Lithuania [19]. Following the principle "electronic document definition - primary, software development - secondary", when ADOC-2.0 specification was created, the supporting software for ADOC-2.0 specification electronic document creation and verification was developed as the software product Signa SDK within product line Signa ${ }^{\mathrm{TM}}$ (Trademark registered in EU).

Electronic document specification ADOC-V2.0 and supporting software ensure the interoperability solution of country-wide electronic documents. Electronic documents of specification ADOC-V2.0 being conformant to the requirements for $\mathrm{ASiC}$-based containers are interoperable in platforms of electronic documents that support ASiC packaging conventions.

\section{B. PDF-Based Document Container}

PDF is the most widely used format for representation of electronic documents. With some exceptions, the PDF format of electronic documents is not country dependent. This means that in many cases national platforms of electronic documents support the PDF format. As a rule, the support of electronic documents of PDF format is product based, i.e., the judgment about validity of electronic document is delegated to PDF processing software. Such an approach lacks the definition of PDF-based electronic document having legal power equal to hand-signed documents in PDF and/or PAdES terms. Therefore, the criteria to determine if a given PDF file is PDFbased electronic document are not defined. The only criterion is particular software as a black box, which classifies "yes/no". If the results of different software systems are different, then it becomes obvious that the definition of PDF-based electronic document does not exist and there is no reference to the recognition problem resolution.

However PDF-based electronic documents are very widespread, the conceptual base for this case of electronic documents is needed. To create such a conceptual base, a definition of PDF-based electronic documents is needed.

PDF-based electronic document can employ a partial document model. Primarily the PDF format has been created for documents of the flat structure from the user's point of view. However, the evolution of document structure has forced to transform the PDF format from a pure document format to a container format. On the other hand, in order to address the needs for extended functionality of signatures, ETSI introduced PAdES signature format as new semantics based on PDF syntax.

It is possible to implement universal document model using PDF-based container, but ZIP-based approach is more suitable for this purpose. However, in the case of simple documents PDF has some advantages. For example, the document can be previewed with widely available PDF readers. But signing and verification of signatures as well as document preparation for long-term retention requires special tools. The main advantage of the PDF-based solution is the simplicity of a document content preview.

Although the solution to base the partial document model on thr PDF format is almost evident, the new standard specification of the electronic document and the tools for complete support of such documents are required. 
Based on the current experience of the Member States, it can be concluded that a partial document model possesses the following properties:

- Flat document content, i.e., consisting of one document;

- Minimal set of metadata;

- Signature always covers the whole document; therefore, the subsequent signatures shall cover not only the content, but the previous signatures as well. Thus, parallel signatures are not allowed.

One of the key points to be discussed is electronic documents metadata and their relation with electronic document itself. International standard ISO 15489-1 [20] specifies "the metadata embedded in, attached to, or associated with, a specific record". This means that according to the standard, metadata can be embedded into a document or attached to a document, or associated with a document. Although this standard allows all kinds of links between electronic documents and its metadata, the electronic document interoperability issues and the need for electronic document automated processing force to use embedded metadata as the integral part of an electronic document.

On the other hand, the requirements of businesses and users are to provide existing electronic documents without metadata to public sector institutions that apply higher requirements for official electronic document processing based on metadata. This circumstance forces to introduce different levels of electronic document compatibility with requirements: a lower level for businesses and citizens and higher - for public sector institutions. It is important to stress that there is a need to transform the same electronic document from a lower compatibility level to a higher one when transferred to a public sector institution.

Such a requirement and other related requirements are incorporated into the definition of PDF-based electronic document specification PDF-LT. The PDF-LT specification conformant electronic document always is a file of PDF format. The electronic signatures of the PDF-LT specification conformant electronic document always are signatures of PAdES format.

PDF-based electronic document specification PDF-LT is approved by the Chief Archivist of the Republic of Lithuania [21]. Supporting software for PDF-LT specification electronic document creation and verification is developed within product line Signa $^{\mathrm{TM}}$ as software product Signa SDK.

\section{Signing in Bulk}

If we consider electronic document usage in Lithuania, one important date is September 7, 2011, when the Lithuanian Prime Minister and the ministers put their first electronic signatures to the legal acts passed by the Government. Since then, the originals of Government decrees have been electronic documents of ADOC specification. The electronic signature system ELPAS allows the Government to save the working time, to electronically sign the legal acts submitted thereto at any convenient time and in any place. The Government also uses ELPAS for the submission of draft Presidential decrees as well as draft laws to the Seimas (Parliament).
The Seimas has started to issue all legal acts as electronic documents since January 1, 2014.

The highest level decision makers need to sign daily dozens of documents. If electronic signing requires more efforts than manual one, a leader will never use the electronic signing.

The "secret" of success is the possibility to sign in bulk the package of electronic documents by once activating a secure signature creation device.

The functionality of signing in bulk is implemented within the product line Signa ${ }^{\mathrm{TM}}$ in software product Signa Docs and in electronic signing system ELPAS of the Government of the Republic of Lithuania developed on the basis of Signa Docs.

These three pillars are as follows: the framework for ZIPbased electronic documents, the framework for PDF-based electronic documents and know-how of visualization and signing in bulk to create sufficient preconditions to address the essential task of cross-border electronic document interoperability.

\section{REQUIREMENTS FOR INTEROPERABILITY SOLUTION}

The most promising way for the interoperability solution of electronic documents is lying in an approach of separate exemplars [16] referred shortly in Section III.

This approach is based on the concept of electronic document exemplar (original identified copy). The identified exemplars of the document are well known in the case of classified documents, for instance, ex. 1 of 3 . It is usual to talk about exemplars (copies) of the parties of agreement. Each party of the agreement can apply his own rules of agreement registration. Therefore, all exemplars of the same agreement have equal legal power but they can differ at some extent. It should be noted that the exemplars could have some minor differences that do not affect the semantics of the document, e.g., the text in the national language.

Each contracting party must possess in own disposition original exemplar of the electronically concluded contract. Each contracting party must be able to provide an exemplar possessed to the authorities or other stakeholders according to the needs or requirements, including the provision of such an exemplar to an archive of electronic documents for preservation.

This means that a contracting party must possess an original exemplar of the electronic document that is conformant to his national platform of electronic documents, i.e., which can be recognized, stored and preserved within the national platform of electronic documents.

The concept of separate electronic document exemplars for each involved national platform of electronic documents can ensure the solution for documents interoperability:

- Separate exemplars of the same document are prepared for each country;

- Each document exemplar is prepared according to the specification of a particular country;

- Each document exemplar is signed using e-signature infrastructure (qualified certificates, OCSP services) of all involved countries. 
Each document exemplar is legally valid in the respective country. Each document exemplar is content, signature and metadata dependent or independent, i.e., these attributes of document exemplars can be identical or can vary. Since the document (exemplar) is in the format specific to a particular country and countries have tools/systems for their official electronic document management, the electronic document (exemplar) is fully functional, i.e., the integrity, authenticity, non-repudiation of the document can be assured and it is possible to transfer such documents to State Archives.

Summarizing, this approach exploits its power when the same document should be signed by the representatives of different countries. A key advantage of this approach is that there is no need for a country to support the document formats of other Member States. Its only notable deficiency is that it requires the separate exemplar per country to be prepared in the national electronic document format.

The key challenge is to provide a solution that is flexible and lightweight enough for the everyday cross-border operations of electronic documents.

Such a solution should provide the user interface to select target countries and electronic document specification within the national platform of electronic documents, including ASiC and PDF/PAdES conformant electronic documents, and define a set of document exemplars to be created as a document package to be signed by document signing parties.

Each signatory signs all exemplars by the activation of a secure signature creation device only once. When a signing procedure is complete, all signatories receive their own document exemplar for the national platform of electronic documents.

The use of electronic documents by third parties can be ensured by services provided by the electronic document owner's country.

\section{SiGNA ${ }^{\text {TM }}$ INTEROPERABILITY PILOTING IN CENTRAL ASIAN COUNTRIES}

Product line Signa ${ }^{\mathrm{TM}}$ interoperability solution that among other EU research results could potentially be transferred to Central Asian countries was analyzed by FP7 project eINTERASIA and selected for further technology transfer piloting.

During eINTERASIA project and two workshops in Astana and Dushanbe, Signa interoperability solution was presented and demonstrated to the local experts using components of a remote electronic signature infrastructure, such as OCSP and time stamping services for mobile and stationary electronic signatures.

In order to validate Signa ${ }^{\mathrm{TM}}$ interoperability, the generic questionnaires on technology transfer from technology developers' and technology acquirers' point of view, as well as on technology to be transferred itself were tailored, the answers collected and analyzed.

As a result, the main Signa ${ }^{\mathrm{TM}}$ interoperability issues were identified related to legal uncertainty caused by missing or incompatible regulation on PKI and hash algorithms and procedures. The analysis of questionnaires filled indicates the most promising route to electronic document interoperability solution in Central Asian countries that involves the establishment of a local network of registration authorities of qualified certification authorities and the ability to create different electronic document exemplars according to the requirements of concerned platforms of electronic documents.

\section{CONCLUSION}

In this paper, we have discussed the cress-border interoperability problem of electronic documents having the same legal power as hand-signed documents. As a result, we have provided the roadmap of cross-border interoperability solution of electronic documents based on the key concepts employed for electronic document interoperability solution - a national platform of electronic documents and original exemplar of electronic document. We have provided the generalized experience of development of product line Signa ${ }^{\mathrm{TM}}$ as a ground for building a new generation of software tool for creation of electronic documents for cross-border operation consisting of three main pillars: the framework for ZIP-based electronic documents, the framework for PDF-based electronic documents and know-how of visualization and signing in bulk.

\section{REFERENCES}

[1] Risztics, P. and Jankovits, I., "Electronic Government and Public Administration in Hungary," in Proc. of the $38^{\text {th }}$ Annual Hawaii Int. Conf. on System Sciences, HICSS05, Track 5, p. 122a, pp. 1-8, 2005. http://dx.doi.org/10.1109/HICSS.2005.228

[2] Koch, B., E-Invoicing/E-Billing 2014. Key stakeholders as game changers, Billentis, Document $\mathrm{N}^{\circ}$ Billentis060514, June 11, 2014. [Online]. Available: www.billentis.com

[3] Volarcvic, M., Strasberger, V. and Pacelat, E., "A philosophy of the electronic document management," Proc. of the $22^{\text {nd }}$ Int. Conf. on Information Technology Interfaces, TI 2000, June 13-16, 2000, Pula, Croatia, pp. 141-146.

[4] "Directive 2006/123/EC of the European Parliament and of the Council of 12 December 2006 on services in the internal market," Official Journal of the European Union, L 376, 27/12/2006, pp. 36-68.

[5] Project "Simple Procedures Online for Cross-border Services (SPOCS)," [Online]. Available: http://www.eu-spocs.eu/

[6] e-SENS (Electronic Simple European Networked Services), [Online]. Available: http://www.esens.eu/home/

[7] Graux, H., "eDocuments and e-Delivery in the context of the services directive. Country Profiles report", European Commission, Internal Market Directorate-General, Brussels, 2009, p. 380.

[8] Kunz, T., Okunick, S. and Viebeg, U., "Long-term security for signed documents: services, protocols, and data structures," Long-Term and Dynamical Aspects of Information Security: Emerging Trends in Information and Communication Security, Nova publishers, pp. 125139, 2007.

[9] Commission Decision of March 172014 N 214/148/EU "Amending Decision 2011/130/EU establishing minimum requirements for the cross-border processing of documents signed electronically by competent authorities under Directive 2006/123/EC of the European Parliament and of the Council on services in the internal market".

[10] ETSI TS 103 171 V2.1.1 (2012-03) Electronic Signatures and Infrastructurs (ESI); XAdES Baseline Profile

[11] ETSI TS 103 173 V2.2.1 (2013-04) Electronic Signatures and Infrastructurs (ESI); CAdES Baseline Profile

[12] ETSI TS $103 \quad 172$ V2.2.2 (2013-04) Electronic Signatures and Infrastructurs (ESI); PAdES Baseline Profile

[13] Document management. Portable document format. Part 1: PDF 1.7, ISO 32000-1:2008, 2008, p. 747.

[14] "PDF/A - the standard for long-term archiving," PDF Tools AG, p. 10, 2009.

[15] Sumroy, R. and Sherrard, B., "Electronic signatures: are we getting there?" Apr. 2012, [Online]. Available: 
https://www.slaughterandmay.com/media/1772936/electronicsignatures-are-we-getting-there.pdf

[16] Antanas, M. and Saulius, R., "Electronic documents interperability solutions in academic environment," in 3rd international workshop on intelligent educational systems and technology-enhanced learning, INTEL-EDU 2012. Riga: JUMI Publishing House Ltd., pp. 21-34, Oct. 10-12, 2012.

[17] Information technology - Open Document Format for Office Applications (OpenDocument) v1.0, ISO/IEC 26300:2007.

[18] ETSI TS $103 \quad 174$ V2.2.1 (2013-06) Electronic Signatures and Infrastructurs (ESI); ASiC Baseline Profile.

[19] Specification ADOC-V1.0 of the electronic document signed by the electronic signature, [Online]. Available: https://signa.mitsoft.lt/static/signa-web/ webResources/docs/ADOC_specification_approved20090907_EN.pdf Valstybès žinios No. 108-4574 (09.10.2009) (in Lithuanian).

[20] Information and documentation - Records management - Part 1: General, ISO 15489-1:2001, 2001, p. 19.

[21] Specification PDF-LT-V1.0 of the electronic document, approuved on August 29, 2014 N VE(1.3 E)-42 by the Chief Archivist of the Republic of Lithuania (in Lithuanian). [Online]. Available: http://www3.lrs.lt/ pls/inter3/dokpaieska.showdoc_1?p_id=480374\&p_tr2=2

Jeremy Besson is a System Analyst and Java Developer at MitSoft company. He sometimes works as a Data Mining Consultant. He is also a Data Mining Lecturer at Vilnius University, the Statistic Department. His research interests focus on developing novel data mining techniques for applications in bioinformatics and digital advertising, and process-oriented innovation and export modelling. He was a key participant of the Baltic Sea Region INTERREG program project BONITA

E-mail: jeremy.besson@gmail.com
Adomas Birstunas is an Electronic Signature Expert and Developer at MitSoft. He is also a Lecturer at the Department of Computer Science of Vilnius University. He received the Doctoral Degree in Informatics from Vilnius University (Lithuania) in 2010. He received the Master Degree in Informatics from Vilnius University in 2004. He joined MitSoft in 2001 and has more than ten years of experience in information systems design, development and maintenance. Deep knowledge of electronic signature and electronic document related standards, their applications and participation in standards development (including European initiatives) allowed him to become an electronic signature and electronic document expert. He is also one of the main MitSoft developers of Signa ${ }^{\mathrm{TM}}$ product line.

E-mail: adomas.birstunas@mitsoft.lt

Antanas Mitasiunas is the founder and chairman of the board of company MitSoft. He is also an Associate Professor of the Department of Computer Science at Vilnius University. He obtained a Doctoral Degree in Computer Science (Dr. sc. comp.) from Moscow State University in 1981. He was a national expert of the ICT Committee in FP7, member of advisory board of the international project Enterprice SPICE, expert of national European Structural Funds. Research areas: process capability maturity modeling, software design, software quality management, innovations and technology transfer.

E-mail: antanas.mitasiunass@mitsoft.lt

Arunas Stockus is a Lecturer at the Department of Computer Science of Vilnius University. He is also a System Analyst and Developer at MitSoft company. His research interests are mainly focused on Internet technologies, web application architectures, as well as electronic document and electronic signature technologies. He contributed to the development of Signa products and to integration of electronic signature support into various information systems.

E-mail: arunas.stockus@mitsoft.lt 